\title{
EPISTEMOLOGI TASAWUF SEBAGAI NILAI UTAMA PEMBINAAN AKHLAK
}

\author{
Hadarah Rajab \\ IAIN Syaikh Abdurrahman Siddik Bangka Belitung \\ Email: hadarah.rajab@iainsasbabel.ac.id
}

\begin{abstract}
Modernist Islam is often seen as not appreciative of the Sufism world as a medium of moral development, but that view is not supported by accurate data. Because Sufism existed for a long time, namely from classical times to modern times marked by the emergence of human rights thinkers who joined Sufism in a modern way although did not specialize in the practice of ketarekatan. Sufism from time to time can be a "fundamental actuality" to become the basis of moral formation as a noble character for individual human beings, socially and even contribute to the pattern of Islam in the country. Nevertheless, the task of scientists, especially those who are constraint in the field of tasawuf both as purification of Sufism morals, as well as for pure spiritual practitioners. All of them need to socialize the primacy of knowledge contained in Sufism and even the practice of Sufism until it is considered to be a driver for the formation of human morals to be noble. Many people do not understand the substantial of Sufism, so it is even likely to be considered a science that can mislead and go out of the path of Islamic teachings. Not a small number of prominent figures make the dimension of Sufism as the main science and moral highest for him, on the basis that aspects of Islam inwardly (intrinsically) can be achieved by living the Islamic shari'a and Faith correctly. Therefore, the essence of starch to Islam dank e-Imanan a person fruitful with moral which began to be called Ihsan, philosophically a good combination of; Islam, Iman and Ihsan is perfect Islamic security (kaffah), and with it make man reached the highest degree of glory, namely Insan Kamil. This achievement requires a genuine struggle (mujahadah), consistent spiritual practice, and maintaining an attitude so as not to deviate from the path and order of divine holiness that has been aspired. Being an interesting study in this article is to achieve an encounter with Ihsan pattern can be easily based on the instructions of Allah SWT., which is often termed as the person who achieved Hidayah Ipetunjuk), but what becomes much more difficult is to maintain it, Istiqamah in His way is a much tougher struggle.
\end{abstract}

Keywords; The Epistemology of Sufism, Main Value of Moral Development, ihsan, hakiki, kaffah, mujahadah

\begin{abstract}
Abstrak
Kalangan Islam modernis acap kali dipandang tidak apresiatif terhadap dunia tasawuf sebagai medium pembinaan moral, namun pandangan tersebut tidak didukung dengan data yang akurat. Sebab tasawuf ada sejak lama, yakni sejak jaman klasik hingga zaman modern ditandai dengan munculnya tokoh pemikir Hamka yang menggandrungi tasawuf-tasawuf secara modern meskipun tidak mengkhususkan kajiannya pada praktek ketarekatan. Tasawuf dari masa ke masa dapat menjadi "fundamental aktualitas" hingga menjadi dasar pembentukan moral sebagai akhlak mulia bagi pribadi-pribadi insani secara individu, sosial dan bahkan turut andil menjadi corak Islam di tanah air. Meskipun demikian, tugas ilmuan khususnya yang konstrasi pada bidang kelimuan tasawuf baik sebagai pemurnian akhlak tasawuf, maupun bagi pengamal spiritual murni. Semuanya perlu mensosialisasikan keutamaan pengetahuan yang termuat dalam dimensi tasawuf dan bahkan praktek sufisme hingga dianggap dapat menjadi penggerak bagi pembentukan akhlak manusia menjadi mulia. Faktanya, banyak kalangan yang belum memahami substansi dari ajaran tasawuf, sehingga bahkan cenderung dianggap suatu ilmu yang dapat menyesatkan dan keluar dari jalur ajaran Islam. Padahal tidak sedikit jumlah tokoh terkemuka yang menjadikan dimensi sufisme sebagai ilmu yang utama dan moral yang tertinggi baginya, dengan dasar bahwa aspek Islam secara batin (hakiki) dapat dicapai dengan menjalankan syariat Islam dan Iman secara benar. Oleh karenanya sari pati ke-Islaman dan keImanan seseorang berbuah dengan akhlak yang mulia yang disebut Ihsan, secara filosopis perpaduan secara baik antara; Islam, Iman dan Ihsan merupakan suatu pengaman Islam yang sempurna (kaffah), dan dengannya menjadikan manusia mencapai derajat kemuliaan tertinggi yakni Insan Kamil. Pencapaian ini memerlukan perjuangan yang sungguh-sungguh (mujahadah), konsisten menjalankan spiritual dan menjaga sikap agar tidak melenceng dari jalur dan tatanan kesucian Ilahi yang telah dicita-citakan. Menjadi kajian menarik pada artikel ini adalah untuk mencapai perjumpaan dengan pola Ihsan dapat dengan mudah berdasarkan petunjuk Allah SWT., yang sering diistilahkan sebagai orang yang mendapat Hidayah petunjuk, namun yang menjadi jauh lebih sulit adalah mempertahankannya, Istiqamah dijalan-Nya adalah suatu perjuangan yang jauh lebih berat.
\end{abstract}

Kata Kunci; Epistemologi Tasawuf, Nilai Utama Pembinaan Akhlak, ihsan, hakiki, kaffah, mujahadah 


\section{Pendahuluan}

Epistemologi merupakan cabang filsafat yang secara khusus membahas tentang teori pengetahuan (theory of knowledge). Kata epistemologi berasal dari bahasa Yunani episteme, artinya pengetahuan. Diantara beberapa persoalan pokok yang bertalian dengan epistemologi adalah apakah sumber-sumber pengetahuan itu, dari manakah pengetahuan yang benar itu datang dan bagaimanakah cara mendapatkan pengetahuan. Apakah sifat dasar pengetahuan tersebut.

Epistemologi merupakan cabang filsafat yang secara khusus menggeluti pertanyaanpertanyaan yang bersifat menyeluruh dan mendasar tentang pengetahuan disebut epistemologi. Istilah "epistemologi" sendiri berasal dari kata Yunani episteme adalah pengetahuan dan logos adalah perkataan, pikiran, ilmu. Kata “episteme” dalam bahasa Yunani berasal dari kata kerja epistamai, artinya mendudukkan, menempatkan, atau meletakkan. Maka, harfiah episteme berarti pengetahuan sebagai upaya intelektual untuk "mendapatkansesuatu dalam kedudukan setepatnya." Selain kata "episteme", untuk kata "pengetahuan" dalam bahasa Yunani juga dipakai kata "gnosis", maka istilah "epistemologi" dalam sejarah pernah juga disebut gnoseologi. Sebagai kajian filosofis yang membuat telaah kritis dan analitis tentang dasar-dasar teoritis pengetahuan, epistemologi kadang juga disebut teori pengetahuan (theory of knowledge; Erkentnistheorie) (Hidayat, 2012).

Epistemologi sebagai teori pengetahuan sebagai cabang filsafat berurusan dengan hakikat dan lingkup pengetahuan, pengandaian-pengandaian dan dasar-dasarnya serta pertanggungjawaban atas pernyataan mengenai pengetahuan yang dimiliki (Rahman, 2012).

Secara umum pertanyaan-pertanyaan epistemologi dapat dibedakan menjadi dua macam, yakni epistemologi kefilsafatan yang erat hubungannya dengan psikologi dan pertanyaan epistemologi semantik yang menyangkut hubungan antara pengetahuan dengan objeknya. Dengan demikian epistemologi meliputi tata cara dan sarana untuk mencapai pengetahuan. Oleh karena itu perbedaan mengenai pilihan ontologis akan mengakibatkan perbedaan sarana yang akan digunakan, yaitu apakah akal, pengalaman, budi, intuisi, atau yang lain. Lebih dari itu ditunjukkan pula kelebihan dan kelemahan suatu cara pendekatan dan batasbatas validitas dari suatu hasil yang diperoleh melalui suatu cara pendekatan ilmiah (Mufid, 2016). 


\section{Metodologi Penelitian}

Artikel ini ditulis memakai pendekatan kualitatif deskreptif terhadap berbagai data dari literature (kepustakaan), jurnal, bookset yang direduksi dari google cendekia (scholarship), media elektorik dan pengamatan langusng atas fakta di lapangan. Literatur sudah banyak yang dulutis dari para tokoh cendekiawan Muslim, Ulama dan para akademisi. Memilih literatur yang relevan dan mendukung tema tentang Filsafat Tasawuf sebagai basis pembinaan akhlak. Meneliti hubungan Filsafat dari aspek Epestiomologi Sebagai Nilai Utama Pembinaan Moral. Literatur Filsafat tasawuf representatif sebagai data utama dan literature pendidikan akhlak juga demikain lengkap, sehingga tulisan ini lebih kaya dalam kajian bila dihubungkan dengan keutamaan kedua unsur keilmuan tersebut dalam rangka pembinaan moral.

Hubungan Filsafat dengan tasawuf menjadi kajian yang menarik; tasawuf sebagai bentuk pengalaman spiritual yang lebih menekankan pada "rasa" daripada "rasio", bahkan sering disebut sebagai ilmu rasa $(d z u q)$ (Badruzaman, 2018). Faktor rasa lebih menonjol daripada rasio itulah mengapa kajian tasawuf tidak mudah dikaji hanya dengan menggunakan upaya nalar dan intelektual. Oleh karena dalam tradisi sejarah pemikiran Islam, terdapat apa yang disebut intuisi, ilham, qalb, dhamir, psikognosis yang kemudian telah dikembangkan secara institusional menjadi tarekat dengan wiridan dan zikir yang baik secara individu maupun berkelompok (Musliadi, 2014).

Hamka menyebutkan tasawuf sebagai disiplin ilmu yang telah mapan di dalam kajian keislaman yang berkembang dari asketisme sederhana pada abad ke-1 dan ke- $2 \mathrm{H}$. bermula dari pribadi kehidupan Nabi Muhammad itu sendiri. Dengan kehidupan ruhani itulah, Nabi Muhammad memiliki jiwa besar. Jiwa besar adalah jiwa yang dekat dengan Tuhan dengan hidayah dari Tuhan, atas karunia Allah SWT. Jiwa besar akan membuka hijab untuk seluruh alam semesta (Najib, 2018).

Tujuan tasawuf adalah membersihkan hati disebut sifa'al-qalb. Pembersihan etika dari perangai-perangai yang tercela, lalu memperhias diri dengan perangai yang terpuji (Najib, 2018). Dalam buku Hamka ia mempertegas bahwa maksud tasawuf semula adalah membersihkan jiwa, mendidik dan mempertinggi derajat budi, menekan segala kelobaan dan kerakusan, memerangi sahwat yang berlebihan (Najib, 2018). dan berfungsi sebagai pembersih jiwa dari pengaruh dunia dan materi sehingga orang mudah menuju Allah SWT (Najib, 2018) sungguh beruntunglah orang yang mensucikan jiwanya dan sungguh merugilah yang mengotorinya (QS. Al-Shams: 9-10) (Departemen Agama, 2009). Penyakit yang paling berbahaya bagi jiwa ialah mempersekutukan Tuhan dengan yang lainnya. Penyakit jiwa lain 
adalah mendustakan kebenaran yang dibawah Nabi Muhammad, memiliki sifat hasud, dengki kepada sesama manusia, benci, dendam, sombong, angkuh dan berbagai sifat negatif padanya. Itulah yang disebut Hamka sebagai kumpulan dosa yang akan membuka segala pintu kepada berbagai kejahatan di level yang lebih besar, (Najib, 2018).

Dapat disimpulkan bahwa tasawuf adalah sebuah upaya pembersihan diri atau jiwa seseorang dari perangai buruk dan dosa. Semakna dengan pendapat Junaid al-Bagdadi, mendefinisikan tasawuf sebagai "keluar dari budi pekerti tercela dan masuk kedalam budi pekerti yang terpuji (Munjiat, 2018). Dengan tasawuf, seseorang akan berupaya membersihkan jiwa, memperbaiki akhlak, memerangi nafsu, serta kerasutan.

Secara aksiologi dalam ilmu tasawuf terdapat dimensi hakiki yakni "dimensi spiritualitas yang terefleksi dalam bentuk tingkah laku. Oleh karena itu tidak berlebihan bila tasawuf yang berkenaan adalah tasawuf akhlaqi. Khozim menyebut karakteristik bentuk dan praktik tasawuf di kalangan modernisme Islam adalah tasawuf akhlaqi transformatif atau tasawuf aktual (Najib, 2018).

\section{Korelasi Tasawuf dengan Syariat}

Pembentukan nilai harmonisasi antara tasawuf dengan ajaran agama yakni Islam, Iman secara simultan harus berjalan seiring komprehensif, tidak menjadi bagian-bagian yang terpisahkan satu sama lain. Sebagai analogi, Sebiji kelapa, terdapat sabuk kelapa, batok, isi dan air, jika ingin mencari minyak pada sebji kelapa tersebut tentunya tidak akan pernah dapat menemukannya, meskipun dalam niji kelapa itu terdapat santan dan minyak. Pada sebiji kelapa terdapat sabuk kelapa iya, sebab sebagaimana fungsi sabuk kelapa demikian penting, batok pada kelapa juga ada, namun apakah pada keduanya ditemukan santan? demikian jioka sudah menemikan isi kelapa belum bias menemujkan minyaknya, sebab membuuhkan proses yang secara berjenjang dalam waktu yang cukup, memerlukan kepiawaian untuk megolah kelapa sehingga menjadi santan, dengan santannya dimasak kemudian menjadi minyak yang wangi dan gurih. Minyak inilah sebagai hasil akhir dair sebiji kelapa. Perumpamaannya bahwa hubungan syariat bagi Iman adalah seuatu kemestian, semata-mata untuk menjadikan manusia terbina berproses dengan penampaan ajaran dan tuntunan nilai-nilai Islam secara lahir dan batin sehingga dapat mencapai akhlak yang terpuji yang merulakan hasil dari perjuangan pada spiritual Islam yakni tercapainya Ihasan.

Menjadi beriman, tidak dapat dipai jika tidak berakhlak yang baik, sedangkan aklak yang baik adalah bentuk dari pelaksanaan ajaran Islam secara lahir dan batin, pelaksanaan 
syariat, hakikat hingga mencapai ma'rifat. Ma'rifat yang dicapai adalah merupakan pengetahuan yang mendalam atas kemaha Kuasaan Allah Swt. Dengan diri hamba, seseorang harus dapat mengetahui benar-benar dirinya sebagai hamba Allah, sebab dengan pengetahun inilah yang dapat meningkatkan derajat kemuliannya, sebab dikatan bahwa barang siapa yang mengetahui dirinya, niscaya ia akan mengetahui Tuhannya dengan baik. Secara Philosopis, manusia menyandarkan dirinya pada Tuhan yang ia sembah seharusnya ia mengetahui dengan Tuhan mana ia bersandar, jika ia hanya menyembah Allah dengan kira-kira, maka yakinlah bahwa ia akan berjumpa Allah secara tidak pasti. Media perjumpaan Allah dengan siri hamba melalui jalur do'a, sedangkan hakikat sholat dan zikir yang lakukan untuk Allah semata-mata untuk menghubgnkan batinnya, hati dan pikirannya secara khusyu'. Lalu kemudian dalam 'hal' kondisi perjumpaan itu muncul rasa dekat dan merasa disambut oleh Allah SWT. Sebagaimana konsep I'tihad al-Junad al-Bagdadi, dalam kondisi ini seseorang merasakan dirinya melayang (tidak berada di bumi), seakan ia ada di alam lain dengan mi'raj melakukan perjumpaan dengan Allah dalam waktu sesaat. Demikan pandangan Jalanuddin Rumi ketika merasakan perjumaannya dengn Tuhan yang disembahnya ia berada pada 'hal' situasasi ruhani yang kedatang Tuhan, hatinya bersemayam dalam dekapan Ilahi, jadi seakan Tuhan turun menghampirinya. Wallau 'a'lam bissawab. Segalanya bias terjadi hanya dengan Kuasa-Nya.

Peranan doa bagi pengamalan ajaran agama bagi kalangan sufi aalah sangat penting. Dan kalimat doa harus penuh penghayatan, misalnya, makna hadis Nabi dalam Shih Bukhari Muslim dikatakan bahwa Engkau menyembah Allah Seakan-akan engkau melihatnya, jika kalaupun engkau tidak dapat melihatnya, cukup yakinlah bahwa Dia melihat engkau. Ini menunjukkan makna bahwa upaya maksimal seorang hamba adalah menyaksikan Allah, itulah upaya yang paling tinggi, lalu dengan apa seseorang bisa mencapainya, disnilah fungsi doa, salah satu contoh kalimat doa yang manjur adalah "ya Allah ya Tuhan kami, bukalah tirai, hijab pembatas antara Engkau dan aku ya Alllah”. Kalimat ini diucapkan berulang kali hingga tersa bahwa hijab pembatas itu telah terbuka. Maka dengan dengan terbukanya hijab itlah disebut orang telah mendapatkan Hidaya dari Allah SWT., sebab mustahil ada kebaikan selain dari hidayah Allah, kemukjisatan dapat terjadi pada siapa saja yang dikehendaki-Nya.

Dari uraian di atas, dengan jelas bahwa akhlak tidak akan baik jika tidak berdasaekan dari pelaksanaan Islam secara baik sebagaimana anjuran al-Qir'an dan al-Hadist, sebab sumber pengetahuan tidak berasal dari manapun kecuali dari kedua aspek tersebut yakni Islam dan Iman, dan daripadanya muncul Ihsaln yang bentuknya adalah akhak mulia, perilaku, Erika, baik untuk sesame makhluk ciptaan Tuhan dan aklak kepada sang Kahliq yakni senantiasa 
menghadirkan Tuhan dari segala gerak geriknya. Merasa selalu dalam pengawan-Nya dan jika hendak melakukan sesuatu, terlebih dahulu melakukan kontak batin dengan Tuhannya yang dalam tasawuf dissebut munajab pada Allah.

Tasawuf sebagaimana yang dimaksudkan dalam tulisan ini adalah interkoneksi secara baik antara tasawuf dengan syariat (Yusub, 2017)' sebab tasawuf yang sesungguhnya adalah yang berlandaskan pada syariat Islam secara benar (tasawwuf mashur'). Oleh karenanya tasawuf yang dibangun yaitu yang tidak melenceng dari ajaran Islam yang selanjutnya disebut tasawuf "fundamental aktualitas". Itulah tasawuf yang Islami sebagaimana yang termaktub dalam al-Quran dan hadis (Hamka, 2016). Menjalankan tasawuf seharusnya sudah otomatis telah menjalankan ajaran Islam secara menyeluruh dengan pencapaian tertinggi ialah sampai pada ma'rifatullah.

Jadi dalam proses perjalan spiritual manusia ia dengan sikap istiqamah di jalan spiritual, tujuan yang ingin dicapai dalam proses ini adalah semata-mata untuk mengenal Allah dang mendekatkan dirinya secara batin. Bagi seseorang yang telah mencapai hal ini, ia tidak memiliki rasa takuit akan segala kemungkian negative yang terjadi pada dirinya. Seorang yang yang telah mencapai akhlak tasawuf tidak pernah merasakan derita akan kurangnya kemewahan dunia, sebab kenikmatan materi hanyalah sebagai pelengkap kebutuhan jasmani bukan untuk kesempurnaan rohaniahnya. Sedangkan kebutuhan rihani semata-mata adalah merasakan dekat dengan Allah SWT., merasakan dekapan-Nya dan batinnya terikat dengan Allah SWT., dalam tingkatan kedekatan hamba dengan Tuhannya dapat dibagi dalam lima bagian yakni; tingaktan hamba yang Liar, Jinak, Patuh,Cinta, Sayang, dan Kasih.

\section{Epistemologi Tasawuf}

Epistemologi tasawuf adalah sumber ilmu pegetahuan dalam bidang tasawuf, sedangkan Epistemologi tasawuf yang dikembangkan dalam artikel ini adalah amalan Islam sebagi aspek batin manusia yang disebut esoterik Islam, mengkaji dari mana asal usul pengetahuan tasawuf, dan bagaiamana transfer pengetahuan yang berkolabirasi Filsafat dan Tasawuf. Dalam suatu penekanan bahwa pengetahuan yang dimaksud adalah pengetahuan yang berlandasakan pada sumber yang shahih yakni yang bersumber dari al-Qur'an dan al-Hadis. Kemudian penjabaran ilmu tasawuf berdasarkan proses pencapaiannya melalui tiga unsur dasar yakni; bersumber dari tasawuf secara klasik yakni; takhalli, tahalli, dan tajalli.(Rohman, 2016) Secara etimologi takhalli (Andiyanto, 2012) berarti melepaskan, mengosongkan dan membebaskan. Pengosongan jiwa menjadi syarat penting bagi proses pembentukan rohani 
seseorang, ibarat bak air sebelum diisi dengan air bersih terlebih dahulu harus melakukan pembersihan rohani terlebih dahulu dalam tasawuf dikenal istilah tazkiyatun nufus yang dilakukan secara berkelanjutan sebagai latihan kerohanian dalam diri seseorang (riyadhah an$n a f s$ ), proses ini menjadi bahagian dari perjalan mencapai hasil yang baik, dan jika tidak melalui jenjang pembersihan rohaniay itu, maka akan sia-sia, segala upaya dan kelelahan mesti dilakukan sebab noda dalam jiwa sudah tersimpan lama mengalami penambahan secara terus menerus hingga menjadi nokhta hitam dan kelam, akibat pencemaran nodah yang tersimpan sejak lama dalam suatu wadah tersebut dalam hati seseorang.

Dalam konteks tasawuf, takhalli merupakan tahapan pertama yang harus dilalui oleh seorang penempuh jalan spiritual yang disebut salik.(Mia, 2020)Takhalli adalah sebuah usaha melepaskan diri dari sifat-sifat tercela. Setelah kosong dan dari akhlak tercela, jiwa manusia harus dihiasi. Tahapan inilah yang dinamakan tajalli yang berupaya menghiasi jiwa manusia dengan sifat-sifat luhur. Dalam proses pembentukan akhlak tasawuf menjadi syarat utama adalah aspek takhalli, tidak bisa meningkata derajat kerohanian manusia jika tidak melakukan pembersihan terlebih dahulu, ibaranya gelas yang kotor tidak akan dapat menjadi wadah air yang sehat dan bersih, jika aira dalam gelas itu diminum, maka akan mencemati orang yang meminumnya itulah ibarat hati yang kotor dapat mencemari orang lain yang berhubungan dengan dirinya, baik dalam lingkungan keluarga, di tempat ia bekerja dan terleb pada pergaulannya sosialnya. Setelah melalui proses pemberihan hati, kemudian diyakini sudah benar-benar bersih dan siap menerima pengetahuan selanjutnya (Fitriani, 2018), maka dia akan naik ke jenjang berikutnya yang disebut tahalli.

Tahapan kedua adalah tahalli, pada proses ini seseorang mulai melakukan pengisian rohani berupa amalan-amalan baik secara berkelanjutan (Hasan, 2020) seperti; melakukan pertobatan, melakukan ibadah secara rutin, zikir dan wirid dengan waktu yang sudah ditentukan, ini menjadi rutinis kesehariannya hingga ia benar-benar sudah istiqamah dengan stasion itu. Kemudian tidak boleh bersikap sombong merasa sudah memiliki amalan dan ibadah yang cukup, sebab dengan perasaan itu sendiri adalah racun bagi dirinya sebagai seorang yang berporses mencapai hakikatyang digunakan dalam istilah tasawuf sama dengan pencapain terting secara substansi dalam dimensi filsafat. dan selalu menjaga amalannya. Menjauhkan diri dari perbuatan maksiat dan terlarang, banyak hal yang tidak mendukung meingkatnya ibadah seorang salik dalam proses tahalli ini, itulah sebabnya banyak penempuh spiritual yang gugur tidak bisa beranjak ke jenjang berikutnya akibatnya terpental kembali ke proses awal pertamakali yaitu takhalli. Kemantapan rohani pada makaqamtahalli ini mejadi dasar yang 
utama bagi pemahaman dasar terhadap sifat-sifat Tuhan. Pencapaian pada pengetahuan secara mendalam salik akan mencapai tingkatan yang disebut ma'rifat.

Tahapan yang terakhir adalah tajalli yang secara literal berarti terlihat atau tampak (Nasution, n.d.). Tajalli merupakan penghayatan kesadaran ketuhanan, Hamka mendefinisikan tajalli dengan makna "kelihatan Allah di dalam hati, bukan di mata, tetapi terasadi hati sanubari bahwa Dia ada" (Melia, 2018). Ini mendeskripsikannya ke dalam kalimat sederhana yang mudah dipahami (tidak pilosofis). Dalam tulisan ini membangun epistemologi tasawuf dengan konsep fundamental aktualitas", dengan yakin bahwa zaman boleh berubah bahkan berganti, namun nilai tasawuf akan selamanya menjadi nafas dan ruh (Irham, 2016) untuk segala zaman tersebut. Penglihatan mata batin terhadap hakikat Tuhan dan alam semestamerupakan bentuk pencapaian atas latihan rohaniah yang senantiasa dilakukan secara berkesinambungan (continu) dan selalu konsisten di jalan spiritual tersebut (Hasan, 2020). Pencapaian pada dimensi tajalli seorang salik akan berada pada pencapaian tingkat akhlak terpuji yang disebut ma'rifatullah yang dengannya ia beradalam dunia fana'. Dunia materi menjadi pernak pernik yang tidak memiliki arti yang penting, namun sebagai sarana hidup untuk mencukupi keperluan dan tidak untuk tujuan hidup. Dunia diletakkan dalam genggaman, sehingga dapat dilemparkan kemana arah yang tepat, dunia dikelolah secara hati nurani, sehingga urusan dunia tidak akan dapat mempengaruhi posisi hari yang sudah bersemayan dalam Ihali.Ilahi anta maksudi wa ridhaqah mat lubhih(Hanya Engkau Tuhan yang dimaksud dan Ridho-mulah yang dituju).

\section{Tasawuf untuk Pembinaan Moral}

Fundamental aktualitas tasawuf berdasarkan pada tauhid,(Sutrisno, 2019)tidak untuk mencari kesaktian dan kekeramatan melalui pengalaman mukasyafah, ketersingkapan tirai pembatas antara manusia dengan Tuhan. Jalan tasawuf ini dibangun atas dasar zuhud, mengapa zuhud itu penting? ini adalah media memudahkan seseorang melakukan peribadatan secara khusyu', (Mustofa, 2011) namun boleh kaya dan memiliki harta jika mampu mengendalikannya dengan arah yang lebih tepat, kekayaan dan kemewahan dunia yang dimiliki menjadi media aktualisasi diri terhadap sesama manusia baik secara individu mapun secara kelembagaan yang berbasis social religius. Itulah bentuk capaian tasawuf aktualitas fundamental.

Perilaku sosial seseorang akan terpatri dengan penghayatan tasawuf (Hasibuan, 2014) berupa pengamalan takwa yang dinamis dan dirasakan langsung oleh orang lain, bukan keinginannya semata-mata mengejar kebersatuan dengan diri bersama Tuhannya semata (hablun minallah), tetapi juga dalam rangka membangun ukhuwah insaniyah (hablun 
minannas) (Wafa, 2016) Juga bukan untuk kekeramatan dan mendapatkan derajat seorang wali yang bersifat magis, metafisis (Shihab, 2020).

Aktualitas fundamental tasawuf adalah semata-mata untuk memperbaiki perilaku dan budi pekerti manusia yang sesuai dengan upaya terhindar dari penyakit jiwa atau penyakit batin dan terbentuknya budi pekerti yang baik di setiap momentum dan zaman.Budi pekerti jahat adalah penyakit jiwa, penyakit batin, penyakit hati (Amir, 2018). Penyakit ini lebih berbahaya dari penyakit jasmani. Orang yang ditimpa penyakit jiwa akan kehilangan makna hidup yang hakiki, hidup yang abadi. Ia lebih berbahaya dari penyakit badan. Dokter mengobati penyakit jasmani menurut syarat-syarat kesehatan. Sakit itu hanya kehilangan hidup yang fana. Oleh sebab itu hendaklah dia utamakan menjaga penyakit yang hendak menimpa jiwa, penyakit yang akan menghilangkan hidup yang kekal (Yuliantoro, 2012).

Berkaitan dengan derajat keimana seorang hamba Allah, sebagaimana penjelasan bagian sebelumnya bahwa terdapat lima golongan atau tingkatan mansia berdasarkan tingkatan keimanannya, yakni, mula-mula manusia bersikap liar, menjadi liar akibat tidak adanya keperluan dengan Tuhan, acuh dengan Tuhan sebab ia tidak memahami arti kedekatan dengan dirinya (Asmaya, 2018). Perlahan dengan melalui proses sosialisasi dan pengaruh lingkangan masyarakat yang terdidik, maka ia mulai megalami perkembangan sehingga ia menjadi jinak, mulaialah ia tenang dan diam dalam suatu kondisi yang bernuansa kajian ke-Islama meskipun ia belum stabil dengan jiwanya sendiri, namun dengan proses demi proses yang ia jalani, kemudian perlahan mulai merasakan kedamaian meskipun terbatas yang membuatnya menjadi patuh. Sikap patuh ini dibina secara terus menerus dengan berbagai latihan jiwa (bersikap sabar, sosial, kreatif, pemaaf dan ikhals) maka mulaialah tumbuh rasa cinta terhadap ajaran agama, mulaialah merasakan benih cinta terhadap Tuhannya (Shihab, 2020).

Kecintaan yang sudah tertanan dalam batin seseorang, ia merasakan keekatan dengan Allah SWT., sudah mulai merindukan kedekatan Allah, senantiasa mengingat-Nya dalam setiap waktu (Isa, 2016). Dan kemudian intensitas memelihara ingatan itu, merasa damai dan tentram dalam batin dengan mengingat Allah secara terus menerus, maka ia mendapatkan derajat yang lebih tinggi yakni 'Sayang', kondisi sayang pada dirinya terhadap Tuhannya membuatnya ia mendapatkan ketengangan batin yang lebih tinggi, selain itu kebutuhan hidupnya tercukupi sehingga urusan dunia menjadi mudah baginya, doadan harapan-harapannya terkabulkan itulah bentuk respond Tuhan atas usaha terhapa hamba yang mencapai takwah bentuknya adalah kemuliaan. Pontesi inilah yang akan mendapatkan derajat tertinggi dari Tuhannya yakni 'Kasih", semakna dengan hadis Qudsi bahwa "hamba-Ku yang Aku kasihi tangan-Ku 
ditangannya tatkalah ia menyentuh, Kaki-Ku di kakinya dikalah ia berjalan, Mulut-Ku di mulutnya dikalah ia berbicara. Maka, siapaun yang akan menganggunya maka Aku akan memeranginya".

\section{Jalan Tasawuf}

Jalan tasawuf adalah merenung ke dalam diri sendiri (Khasani, 2020). Membersihkan diri dan melatihnya dengan berbagai macam latihan yang disebut dalam tasawuf riyadhat alnafs, dengan ini ditelatenkan dalam waktu lama, maka akan terbukalah selubung diri sendiri lalu muncullah cahaya yang gemilang”. Sejalan dengan pandangan tasawuf Hamka bahwa kehidupan bertasawuf tidaklah seperti yang dipahami dan digambarkan oleh sebagian sufi hingga melemahkan gerak manusia, dan melupakan manusia dari kehidupan dunia (Yuliantoro, 2012).

Kehidupan rohani dapat dimiliki oleh seseorang walaupun tidak menjadi Biara bagi nasrani,(Yuliantoro, 2012) atau tidak melakukan suluk bagi muslim. Namun kehidupan rohani adalah bentuk keinsafan, bahwa alam ini bukanlah semata-mata terdiri dari benda. Pendirian keruhanian ini tidaklah mengakibatkan melemahnya perjuangan hidup seseorang (Mulyadin, 2020). Atau menyepikan diri dari masyarakat bahkan melarikan diri ke tempat sunyi dari keramaian. Atau bahkan putus asa dan membenci kepada kehidupan dunia. Namun pengakuan tulus tentang kuasa Ilahi adalah menimbulkan kesungguh-sungguhan dalam segala pekerjaan yang dihadapi. Menimbulkan semangat yang dinamis dan berapi-api. Menyebabkan timbulnya sikap ikhlas dan jujur (Mashita, 2018).

Setiap diri manusia yang terdiri dari unsur materi jasmani dan non-materi (rohani) membutuhkan asupan rohani, tidak sekedar pemenuhan kebutuhan jasmani (Aprilia, 2017). Dalam hal ini, manusia membutuhkan tasawuf. Dengan demikian bertasawuf merupakan upaya penyempurnaan wujud kerohanian manusia. Dalam konteks ini menegaskan bahwa tasawuf merupakan usaha pelakunya untuk keluar dari akhlak tercela menuju akhlak terpuji (Najib, 2018).

Menyimak uraian di atas, maka atas dasar itulah, Dawan Raharjo menarik kesimpulan dengan mengaitkan pandangan Hamka, bahwa dengan tasawuf modern Hamka adalah meletakkan tasawuf kepada relnya, dengan menegakkan kembali tujuan awal tasawuf yakni guna membersihkan jiwa, mendidik, dan memperluas perasaan. Menghidupkan hati dalam menyembah Tuhan dan mempertinggi derajat budi pekerti (Muvid, 2019). Karakteristik dalam kajian inidentik dengan karakteristik tasawuf yang dikonsepsikan oleh al-Taftazani. Menurut 
al-Taftazani tasawuf memiliki karakteristik yang bersifat moral, psikis, dan epistemologis (Najib, 2018).Terdapat lima karakteristik tasawuf antara lain,

Pertama, peningkatan moral Tasawuf memiliki moral tertentu yang bertujuan membersihkan moral. Tasawuf memiliki moral tertentu yang bertujuan membersihkan jiwa agar dapat bertemu dengan Dzat Yang Maha Suci. Tanpa Moral, tasawuf tidak ada. Ibn alQayyim melandaskan tasawuf adalah moral. Menghilangkan sifat tercela dan menghiasi dengan sifat mulia merupakan tahap awal peningkatan moral dalam tasawuf. Tahapan yang berjenjang dalam peningkatan moral disebut maqamat.

Kedua, fana dalam realitas mutlak. Dalam tasawuf "kesatuan" Tuhan dengan hamba merupakan sesuatu yang memungkinkan. Sebab tanpa "bersatu" dengan Tuhan, tasawuf berkutat dengan moral. Jalan menuju Tuhan dalam tahap berjenjang hingga terwujud "kesatuan" paripurna yang menegaskan tiada yang ada, kecuali Tuhan tasawuf merupakan tanjakan spiritual menuju Tuhan, Dzat yang Maha Ada.

Ketiga, pengetahuan intuitif langsung dari Tuhan. Ini merupakan titik perbedaan antara filsafat dan tasawuf. Bila filsafat mencoba berpikir secara mendalam dan radikal, tasawuf memperoleh pengetahuan melalui dengan jalan kashf atau intuisi. Kashf sufi tidak dapat dirumuskan dengan kata-kata karena hasilnya berupa dawa, hasil cita rasa, dan bersifat subjektif. Para sufi melukiskan kashf bagaikan kilat yang tiba-tiba muncul dan hilang.

Keempat, kebahagiaan dan ketentraman jiwa. Pengendalian hawa nafsu, penyucian jiwa, dan berbagai awal yang dilakukan sufi mendorong pudarnya rasa takut sekaligus melahirkan ketentraman jiwa. Ketakutan memudar karena keyakinan yang tegas tentang Tuhan Dzat yang Maha Ada. Kebahagiaan muncul sebab jiwa terbatas dari penjara nafsu. Bagi sufi tertentu "bersatu" dengan Tuhan merupakan kebahagiaan yang tidak terpatrikan, dan mustahil diungkapkan dengan kata-kata.

Kelima, penggunaan simbol dalam berbagai ungkapan. Tasawuf memiliki kekayaan melimpah ruah dalam persyaratan untuk pengungkapan kecintaan kepada Tuhan dan lain-lain. Setiap sufi mempunyai cara tensendiri dalam menuangkan pengalaman subjektif yang dialaminya. Karena itu, dalam tasawuf banyak ditemui syair dan nyanyian yang indah. Tidak berlebihan bila tasawuf dekat dengan seni. Kadang-kadang ungkapan tasawuf, dibutuhkan pemahaman dari etimologi dan analisa mendalam. 


\section{Berdasarkan al-Qur'an dan Hadits}

Pada bagian ini merupakan penekanan dan pengembalian tasawuf dalam dekapan syari'at yang berdasarkan al-Qur'an dan al-Hadits. Sekalipun tidak berurutan seperti dalam maqamat dan ahwal dalam tasawuf klasik, konsep perjalanan menuju Tuhan dengan memerangi hawa nafsu. Hawa nafsu adalah musuh utama yang menghalangi manusia mencapai keutamaan. Hawa nafsu bergerak atas dasar keinginan rendah manusia dan menjauh dari kebenaran. Gara-gara hawa nafsu, manusia akan menjadi setan bagi dirinya sendiri.Karena itu, memerangi hawa nafsu adalah jalan yang harus ditempuh agar manusia tidak kehilangan kemanusiannya dan mengenal Tuhan (Sutoyo, 2015).

Perang melawan hawa nafsu berlangsung sepanjang manusia hidup, dan medan perang itu dalam diri manusia sendiri. Manusia yang mampu mengalahkan hawa nafsu akan menjadi manusia utama. Sebab, manusia seperti itu akan menjadi manusia utama. Sebab, manusia seperti itu akan menjadi raja bagi dirinya, dan hawa nafsu akan menjadi budaknya (Riyadi, 2016).

Manusia memiliki potensi untuk mengalahkan hawa nafsu. Sebab, Tuhan memberi manusia akal. Hawa nafsu membawa kepada bahaya, meskipun jalannya mudah. Sebaliknya, akal mengantarkan kepada kemuliaan dan keutamaan (Alfurqan \& Harmonedi, 2017), kemampuan manusia untuk memilih antara hawa nafsu dan akal menentukan siapa yang memenangkan pertarungan.

Merasa cukup dengan pemberian Tuhan adalah kekayaan yang sebenarnya. Sebab bagi orang qana'ah, kekayaan sekedar terletak di tangan, tidak merasuk dalam hati. Orang yang qana'ah akan bersemangat mencari karunia Tuhan. Sebab, mencari karunia Tuhan adalah ibadah. Namun, setelah mendapatkan karunia Tuhan, kekayaan tersebut tidak pernah bersemayam dalam hati orang yang qana'ah.

Merasa cukup dengan pemberian Tuhan adalah kekayaan yang sebenarnya. Sebab, bagi orang qana'ah, kekayaan sekadar terletak di tangan, tidak merasuk dalam hati.Orangyangqana'ah akan bersemangat mencari karunia Tuhan. Sebab, mencari karunia Tuhan itu adalah ibadah. Namun, setelah mendapatkan karunia Tuhan, kekayaan tersebut tidak pernah bersemayam dalam hati orang yangqana'ah.

Tahapan selanjutnya adalah tawakkal, prinsip tawakkal yang dibangun bukan tawakkal yang fatalistik (qadariyyah). Namun ikhtiar juga bukan segala-galanya. Tanpa kehendak 
Tuhan, tidak ada ikhtiar yang sanggup mencapai kesuksesan. Dalam pengertian tawakkal berlandaskan pada prinsip ketauhidan yang sempurna.

Tahapan paling akhir adalah ikhlas. Yang merupakan kumpulan ungkapan berbagai makna kebaikan di dalamnya yaitu; bersih, murni dan tidak ada campuran, ibarat emas tulen. Pekerjaan yang bersih terhadap sesuatu dinamakan al-ikhlas. Melakukan sesuatu semata-mata karena Tuhan, dan bukan dengan suatu instrik-instrik karena mencari perhatian dan pujian dari seseorang. Termasuk melakukan ibadah semata-mata hanya karena Allah semata. Lawan dari ikhlas adalah syirik yang berarti menyekutukan atau mencampurkan sesuatu dengan yang lain. Ikhlas dan syirik ini tidak dapat disatukan sebagaimana tidak dapat dipertemukannya antara gerak dan diam.

Tasawuf merupakan agent of social cange dari segala macam keterpurukan hidup umat manusia yang pada akhrinya membawa pada kehidupan yang tenang, aman dan selamat dan damai yang menjadi sejahtera dan bahagia. Ini tidak hanya spiritualitas semata yang sekedar pelarian psikologis (eskapisme) serta obsesi untuk pemenuhan kebutuhan rohani sesaat. Lebih penting dari itu adalah tasawuf memberikan long lastingspiritual values yang bersifat duniawi dan ukhrawi. Inilah jalan sejatinya yang ditempuh para pencari Tuhan di masa silam.

Pada bagian ini mengaskan bahwa yang dapat memenuhi spiritual manusia hanyalah agama melalui dimensi esoterismenya. System ideologi apapun, yang ditegakkan oleh manusia, yang menafikan kenyataan bahwa manusia tidak hanya mengejar materi semata. Melainkan ia akan mengalami krisis bahkan kehancuran. Manusia mungkin biasa hidup dalam system yang baru, namun jiwanya tetap dikendalikan oleh fitrah-firtah yang tidak dapat dijelaskan dan dipuaskan secara materialistik.

Jika material yang menjadi tujuan utamanya, maka menjadi cikal bakal perubahan pola hidup menjadi "manusia modern dan sekuler", yang justru menjadikan manusia menjauh dari nilai-nilai kebaikan, akan muncul keinginan yang berlebihan untuk berkuasa, menjadi hedonistic yang melulu mencari kenikmatan dunia. Menjadi serakah dan jauh dari sikap sosial. Waktu yang mengendalikan hidupnya sehingga tidak dapat berbagi untuk ibadah dan menjaga kesehatan. Pada akhirnya menimbulkan kekosongan jiwa dan kegersangan hati, spritualitas menjadi beku, bukan menjadi tercerahkan. 


\section{Kesimpulan}

Epistemologi Tasawuf Sebagai Nilai Utama Pembinaan Akhlak patut diapresiasi secara wajar terhadap dimensi esoteric Islam sebagai tameng ketauhidan, dan menjadikan "tasawuf fundamental actuality"untuk penjelmahan batin dan lahirnya, itulah media untuk mencetak moral secara pribadi seseorang, moral masyarakat dan moral bangsa untuk menjadi "tangguh". Capaian ini menjadi babak baru sufisme era Millenial. Otak, Wawasan dan Performa menjadi modern, namun sikap dan moral menjadi tauladan, mencerahkan dan menjadi pengayom yang mendamaikan.

Seluruh manusia di bumi akan mengikuti arus peruubahan secara alamaiyah itu sudah menajdi bagian dari sunnatullah. Tidak bisa menyalahkan segala bentuk perubahan baik itu positif maupun negative, sebab sejatinya sebuah perubahan akan disertai dengan hal-hal belum tentu dapat digeneralisasi, belum tentu setiap perubahan berbuah manis, diperlukan filter yang tebal, perlu penyaringan yang ketat itulah perlunya akhlak yang permanen. Tugas manusia adalah menjalani dan menelola hidup dan berdamai dengan segala perubahan zaman, oleh karena manusia hidup akan selalu selara dengan zamannya, tidak bisa hidup masa kini dengan pola masala lampau yang sudah tidak relevan.

Banyak faktor kehidupan yang memang harus disesuaikan dengan jaman, namuan perlu kewaspadaan yang tingggi terahdap arus golobalisasi ini, perlu penyesuaian dengan tatanan hidup sebagai insan agamis, tatanan berbangsa dikarenakan setiap Negara dan agama memiliki norma tersendiri, demikian pada setiap bangsa terdapat budaya sebagai kciri hasnya yang disebut locam wedoom. 


\section{Referensi}

Alfurqan, A., \& Harmonedi, H. (2017). Pandangan Islam Terhadap Manusia: Terminologi Manusia dan Konsep Fitrah serta Implikasinya dengan Pendidikan. Jurnal Educative: Journal of Educational Studies, 2(2), 129-144.

Amir, A. N. (2018). Ibn abī dunyā dan sumbangannya dalam pemikiran tasawuf [ibn abī dunyā and his contribution in islamic sufism]. Al-qiyam International Social Science and Humanities Journal, 1(1), 24-32.

Andiyanto, T. (2012). Konsep epistemologi irfani dalam kaitannya dengan ilmu tasyawuf. ArRusyd, 2(2), 43-57.

APRILIA, E. K. A. (2017). Realisasi kecerdasan spiritual dalam kajian psikologi transpersonal dan tasawuf modern (study kasus pengurus germusa iain tulungagung).

Asmaya, E. (2018). Hakikat manusia dalam tasawuf al-ghazali. KOMUNIKA: Jurnal Dakwah Dan Komunikasi, 12(1), 123-135.

Badruzaman, D. (2018). Perkembangan Paradigma Epistemologi dalam Filsafat Islam. KACA (Karunia Cahaya Allah): Jurnal Dialogis Ilmu Ushuluddin, 8(2), 155-171.

Departemen Agama, R. I. (2009). Mushaf al-Qur'an dan Terjemah. Jakarta: Pustaka AlKautsar.

Fitriani, N. (2018). Nilai-nilai sufistik dalam novel dibawah lindungan ka'bah karya hamka. UIN Raden Intan Lampung.

Hamka. (2016). Hamka, Tasawuf: Perkembangan dan Pemurniannya, (Jakarta: Penerbit Republika, 2016), 321.

Hasan, M. N. A. Bin. (2020). Kondisi sosial dan spiritual anak bina inabah XV pasca rehabilitasi. Istiqamah: jurnal ilmu tasawuf, 1(1), 30-45.

Hasibuan, a. (2014). Paradigma pendidikan berbasis akhlak tasawuf. Forum paedagogik, 6(02).

Hidayat, A. (2012). Epistemologi Carok (Refleksi terhadap Struktur Dasar Kesadaran dalam Aktivitas Manusia Mengetahui). Karsa, 54-67.

Irham, M. I. (2016). Nafas kesadaran dan menghidupkan spiritualitas melalui integrasi tasawuf dan psikologi. Teosofi: Jurnal Tasawuf Dan Pemikiran Islam, 6(1), 117-138.

Isa, A. Q. (2016). Hakekat Tasawuf. Qisthi Press.

Khasani, F. (2020). Tasawuf kontemplatif: prinsip-prinsip jalan kesufian al-muhasibi. Dinamika Penelitian: Media Komunikasi Penelitian Sosial Keagamaan, 20(2), 285-312.

Mashita, I. A. (2018). Tasawuf modern: studi komparasi pemikiran antara Hamka dan Nasaruddin Umar. UIN Sunan Ampel Surabaya.

Melia, N. (2018). Kebahagiaan Dalam Perspektif Tasawuf (Analisis Perbandingan Antara AlGhazali dan Buya Hamka). IAIN Bengkulu.

Mia, K. (2020). Penanaman nilai-nilai spiritual dalam kegiatan tarekat qadiriyah naqsyabandiyah (tqn) di lembaga dakwah tqn suryalaya kabupaten banyumas. IAIN Purwokerto.

Mufid, F. (2016). Radikalisme Islam dalam Perspektif Epistemologi. Addin, 10(1), 61-82.

Mulyadin, W. (2020). Nilai-nilai pendidikan islam pada pemikiran tasawuf. KreatiF: Jurnal 
Studi Pemikiran Pendidikan Agama Islam, 18(1), 1-16.

Munjiat, S. M. (2018). Peran Tasawuf Dalam Pendidikan Karakter. Al-Tarbawi Al-Haditsah: Jurnal Pendidikan Islam, 3(2).

Musliadi, M. (2014). Epistemologi Keilmuan dalam Islam: Kajian terhadap Pemikiran M. Amin Abdullah. Jurnal Ilmiah Islam Futura, 13(2), 160-183.

Mustofa, A. (2011). Khusyu'Berbisik-bisik Dengan Allah (Vol. 26). Padma press.

Muvid, M. B. (2019). Strategi Dan Metode Kaum Sufi Dalam Mendidik Jiwa: Sebuah Proses untuk Menata dan Mensucikan Ruhani agar Mendapatkan Pancaran Nur Illahi. Goresan Pena.

Najib, M. A. (2018). Epistemologi Tasawuf Modern Hamka. Dinamika Penelitian: Media Komunikasi Penelitian Sosial Keagamaan, 18(2), 303-324.

Nasution, I. F. A. (n.d.). Wahdat al-wujûd dalam alquran.

Rahman, A. (2012). Pendidikan Agama Islam dan Pendidikan Islam-Tinjauan Epistemologi dan Isi-Materi. Jurnal Eksis, 8(1), 2053-2059.

Riyadi, A. K. (2016). Abdul Kadir Riyadi, Arkeologi Tasawuf; Upaya Menyeruak yang Tersembunyi, (Bandung: Mizan, 2016), 117-119.

Rohman, M. A. A. (2016). Pendidikan islam dalam perspektif epistemologi burhaniy. Qalamuna: Jurnal Pendidikan, Sosial, Dan Agama, 8(02).

Shihab, M. Q. (2020). Dia dimana-mana:" Tangan" Tuhan di balik setiap fenomena. Lentera Hati Group.

Sutoyo, S. (2015). Tasawuf Hamka dan rekonstruksi spiritualitas manusia modern. Islamica: Jurnal Studi Keislaman, 10(1), 108-136.

Sutrisno, E. (2019). Aktualisasi Moderasi Beragama di Lembaga Pendidikan. Jurnal Bimas Islam, 12(2), 323-348.

Wafa, M. S. (2016). Motivasi beribadah dan perilaku sosial jamaah IPKA Salatiga (Ikatan Pensiunan Kementerian Agama) Salatiga 2016. Fakultas Tarbiyah dan Ilmu Keguruan.

Yuliantoro, S. (2012). Penanaman nilai-nilai budi pekerti pada anak melalui kesenian tradisional. Candi, 4(2).

Yusub, F. H. (2017). Interkoneksi Sufi Klasik Dan Kontemporer (Mengenal Sufisme Islam). Fikrotuna, 5(1). 